\title{
رؤية مستقبلية لتطوير التعليم قبل الجامعي في مصر والكويت
}

\section{A future vision for the development of pre-university education}

in Egypt and Kuwait

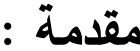

يعتبر التعليم Education حق من الحقوق الأساسية اللازمة لكل أفراد المجتمع، وهذا يستلزم

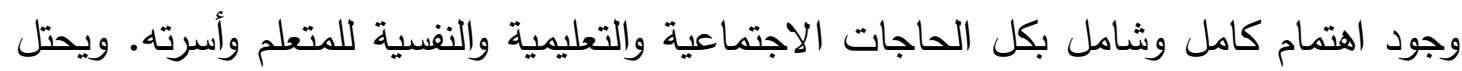

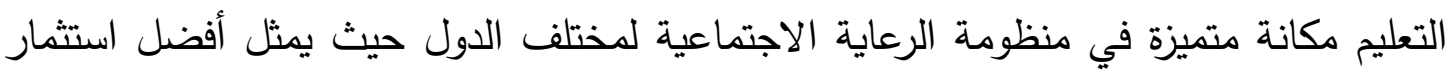

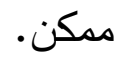
والمدرسة School إحدى المؤسسات التعليمية التي تقدم الخدمات التعليمية للتلاميذ بدءاً من سن

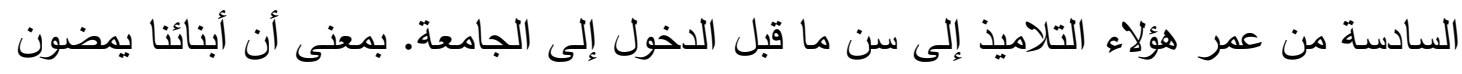
في المدرسة فترات طويلة من عمرهم ليحصلوا على العلم والمعرفة والتربية السليمة. ويعد التعليم من أهم ركائز التمية البشرية Human Development في أي مجتمع لمعل لما يؤديه

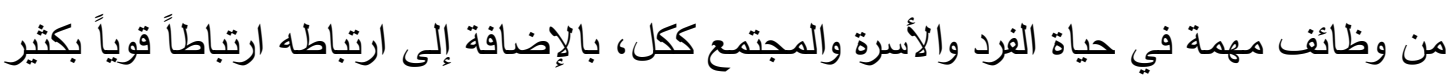

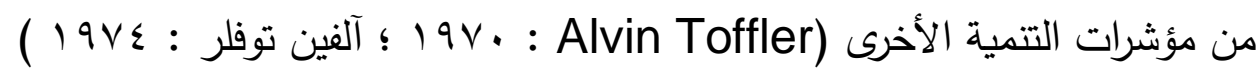
وكذا فإن الاستثمار Investment في التعليم يحتاج إلى رؤية مستقبلية Future Vision جديدة : تونية تهدف إلى تتمية البشر اجتماعياً. وتركز معايير العمل في مجال التتمية البشرية على زيادة فعالية

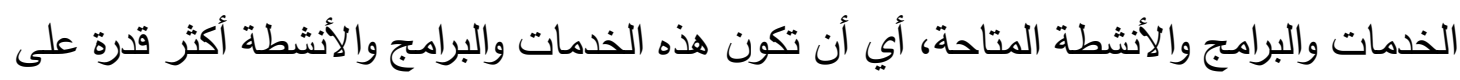
تلبية حاجات التلاميذ والطلاب ومواجهة مشكلات المجتمع ( اليونسكو : V V V ) ).

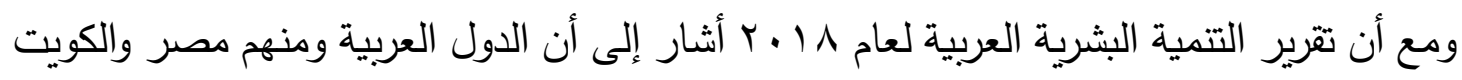

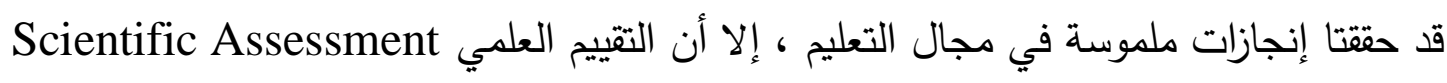

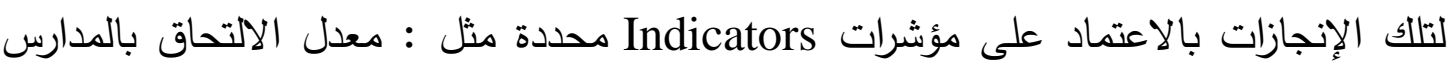
وحجم الإنفاق على التعليم يكثف عن وجود مجالات مهمة بحاجة إلى مزيد من التقدم فيها، إضافة لإنة

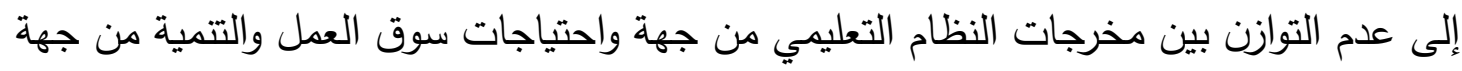

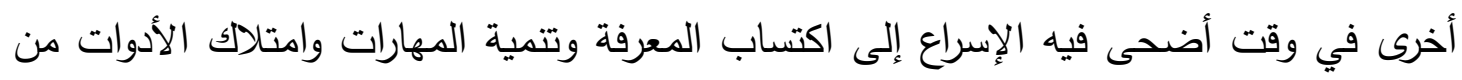
الشروط الأساسية لتحقيق التقدم.

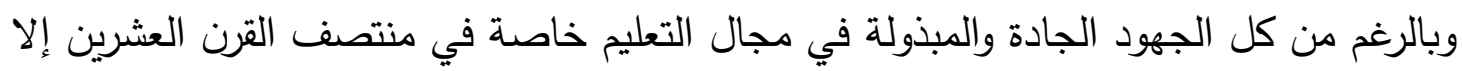
أن ما وصل إليه التعليم في الوطن العربي حتى بالمعايير التقليدية - لا يزال متواضعاً مقارنة

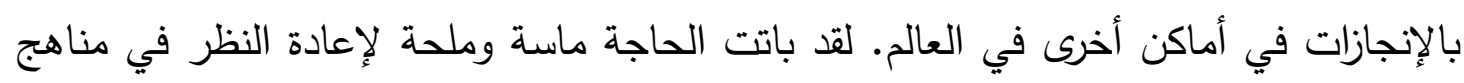


وطرق التعليم المعمول بها في مؤسساتتا التعليمية ، وتخليص تلك المناهج من الحشو الذي لا

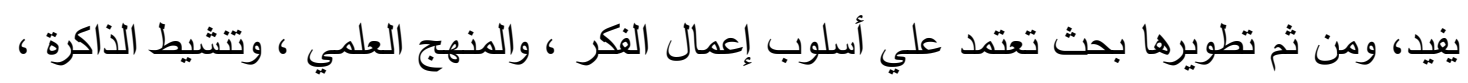

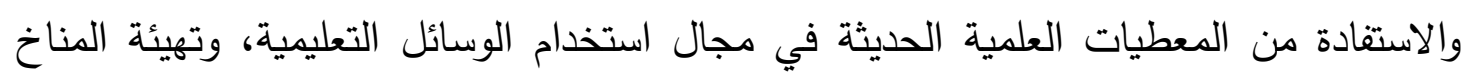

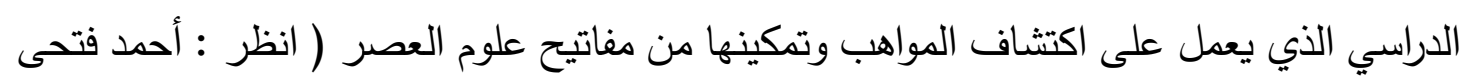

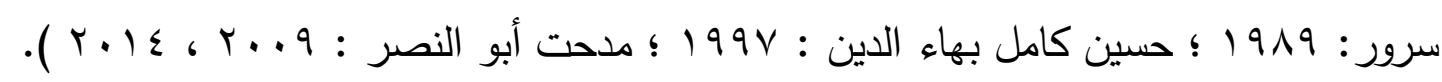

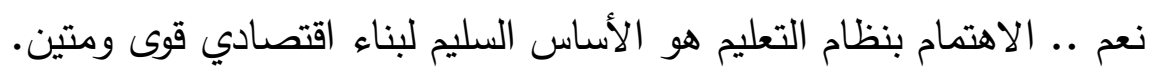

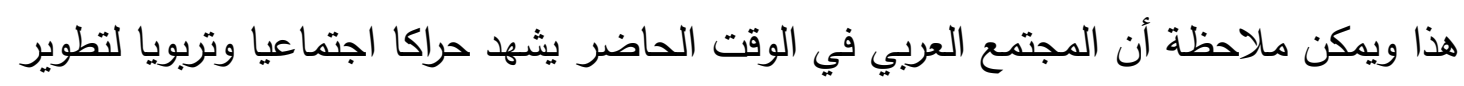

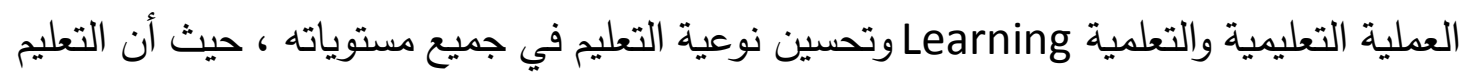

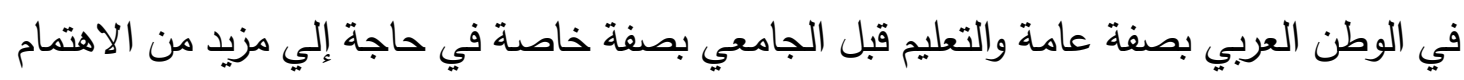

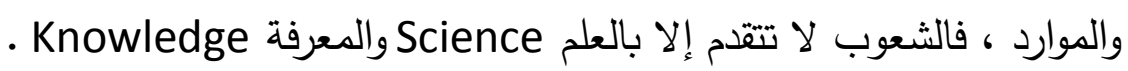

ولقد بدأت كثير من الدول العربية ومنهم كل من مصر والكويت بإعطاء مزيد من الاهتمام وتوفير

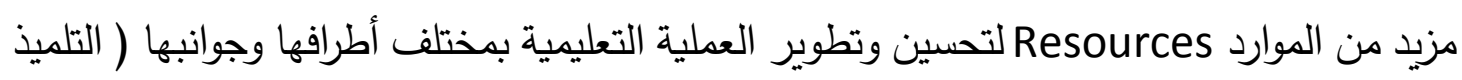
أو الطالب والمعلم والكتاب المدرسي والأنشطة والامتحانات والمدرسة....) في مؤسسات التعليم قبل

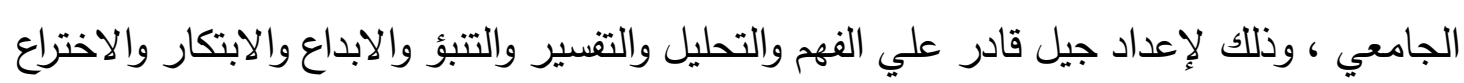
، جيل يؤمن بالقيم الدينية والأخلاقية وبالمواطنة والوسطية والتفكير الايجابي والمتفائل ... ومن هنا سوف يحاول البحث الحالي تقديم رؤية مستقبلية لتطوير التعليم قبل الجامعي في مصر والكويت. وهذه الرؤية جاءت من خلال رصد الواقع في مؤسسات التعليم قبل الجامعي ومن خلال معايشة التحديات والمعوقات التي تعوق مؤسسات التعليم قبل الجامعي عن تحقيق أهدافه التعليمية

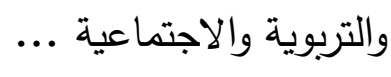

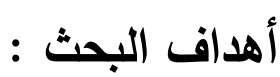

يهدف البحث الحالي إلي تقديم رؤية مستقبلية لتطوير وتحسين التعليم قبل الجامعي في مصر والكويت. أهمية البحث : تتمثل أهمية البحث في تقديمه مجموعة من التوصيات التي يمكن أن تساهم في تطوير وتحسين التعليم قبل الجامعي في كل من مصر والكويت ، والذي يؤدي بدوره إلي تحسين مخرجات التعليم قبل الجامعي ، وبالتالي تحسين مدخلات التعليم الجامعي. 
كيف يمكن تطوير وتحسين التعليم قبل الجامعي في مصر والكويت ؟ التعليم قبل الجامعي : يقصد بالتعليم قبل الجامعي التعليم والتعلم الذي يقدم قبل المرحلة الجامعية ، وذلك للأطفال في

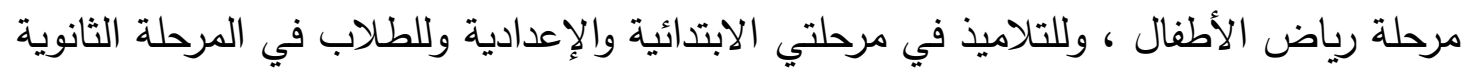

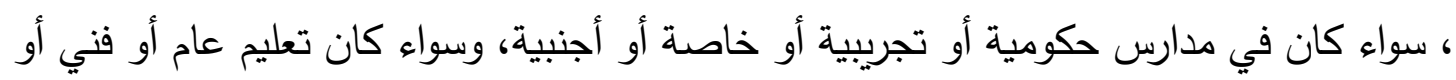

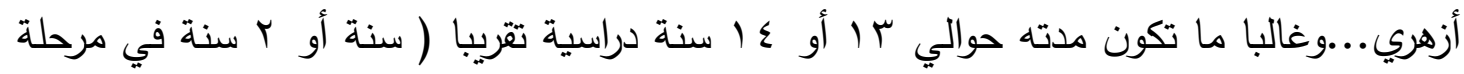

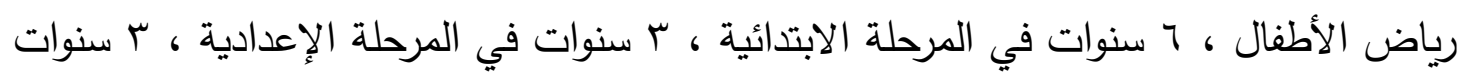

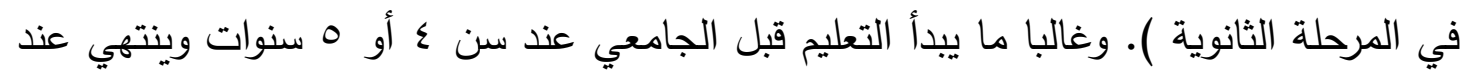
سن ر1 سنة.

وبالتالي فإن مرحلة التعليم قبل الجامعي تشغل كل مرحلة الطفولة ( من يوم إلي أقل من بـ إسنة

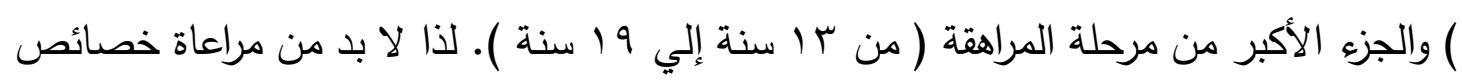

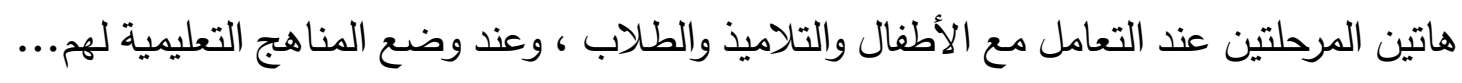

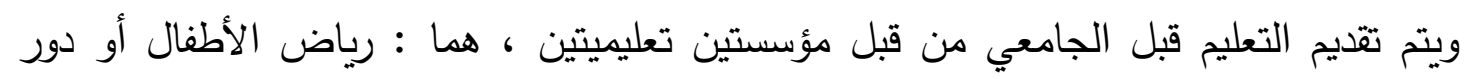

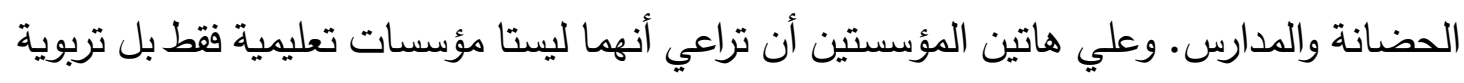

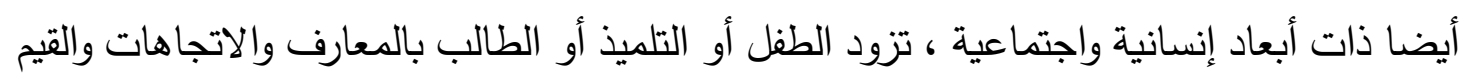

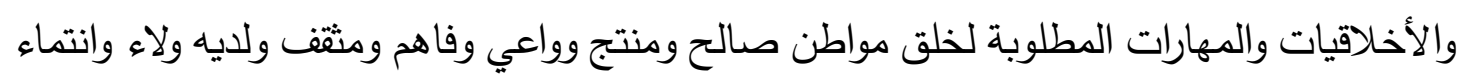
للمجتمعه ...

ومخرجات التعليم قبل الجامعي هي مدخلات التعليم الجامعي. وهذا معناه ضرورة الاهتمام بالتعليم

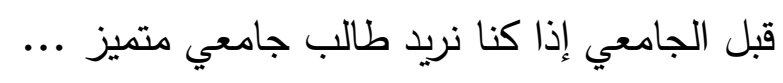
الرؤية المستقبلية : المعني اللغوي لدفهوم الرؤية Vision كما جاء في قواميس اللغة العربية هي :

$$
\text { 1- أبعل حس بصري }
$$

r ب- ب- نظرة مستقبلية للأكام ع - تعتمد على البصيرة والاستبصار

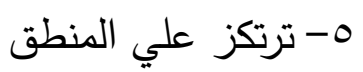




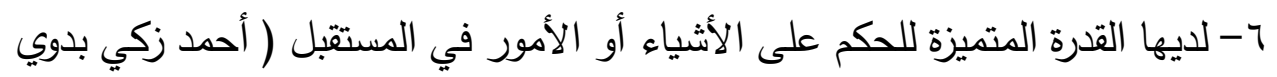

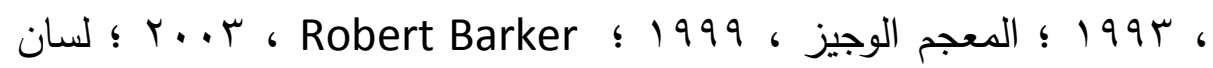

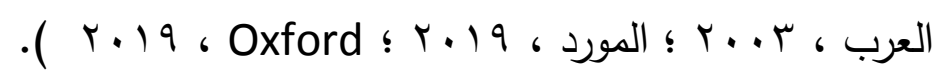

ومن تعريفات الرؤية المستقبلية أنها :

1- بلم تريد المنظمة أو المجتمع تحقيقه.

r- تطلعات وطموحات المنظمة أو المجتمع.

r- جسر ما بين الحاضر والمستقبل تصف المستقبل المنشود وليس المستقبل الذي يمكن

$$
\text { توقعه. }
$$

ع- صورة ذهنية واضحة لمستقبل مرغوب فيه ( Lane Jenning ، سوفه بو 199 ؛ مدحت أبو

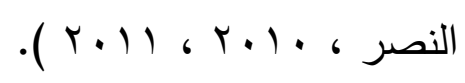

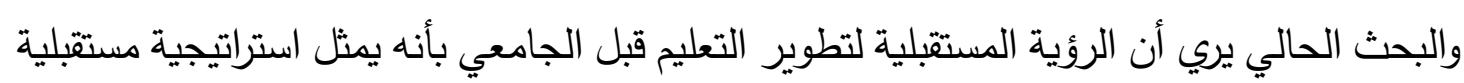

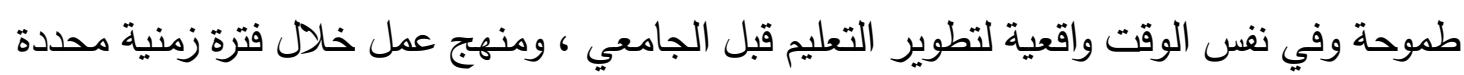

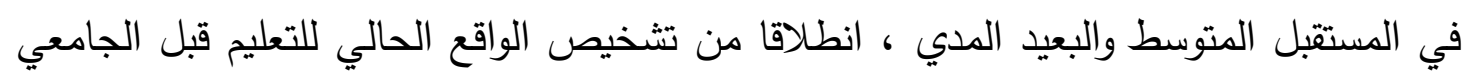

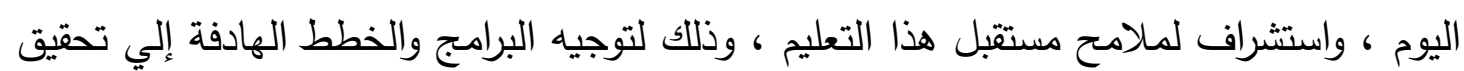

$$
\text { هذا التطوير ( سهام القبندي : } 9 \text { ( ب ب ). }
$$

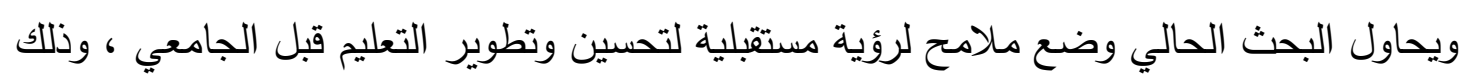

من خلال اقتراح تطبيق المحاور أو الآليات التالية :

$$
\begin{aligned}
& \text { 1- المدرسة الصديقة } \\
& \text { r- المدرسة الذكية } \\
& \text { ץ- المدرسة المنتجة } \\
& \text { ع - المدرسة الخضراء }
\end{aligned}
$$

H - المدرسة التي تطبق نموذج

7- الأنشطة المدرسية

V- تتمية الابداع والابتكار والاختراع لدي التلاميذ والطلاب

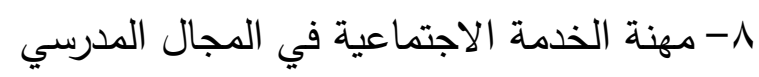

ومن أهم مصادر هذه الرؤية المستقبلية :

1- دستور كل من جمهورية مصر العربية ودولة الكويت

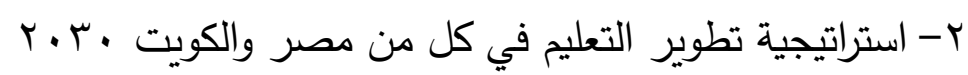

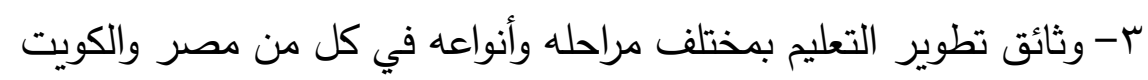




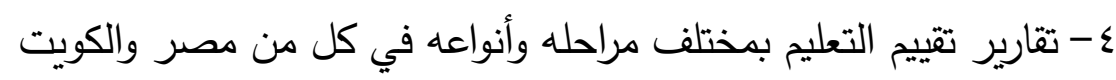

$$
\text { †- التفكير المستقبلي التفاؤلي }
$$

V - فلسفة ممارسة مهنة الخدمة الاجتماعية في المجال المدرسي

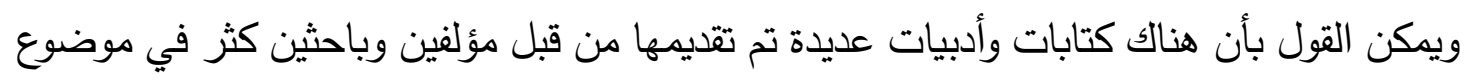

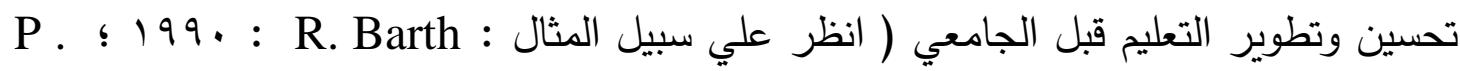
؛ r.V : S. Purkey \& M. Smith ؛ 199 : Sarah Peeper ؛ 199 : Dalin

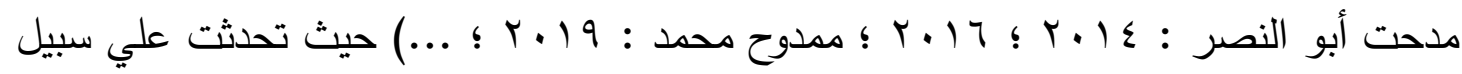
المثال عن : مدرسة المستقبل ، المدرسة الحديثة ، المدرسة الجيدة ، الددرسة الفعالة ، كيفية تطوير المدارس ، كيف نجعل التلاميذ والطلاب يحبون المدرسة ؟ ، تطوير العملية التعليمية ، الوظائف التعليمية والاجتماعية والمجتمعية للمدرسة ، ... وسيتم الاستفادة من هذه الكتابات والأدبيات في عرض المحاور والآليات السابق الاشارة إليها.

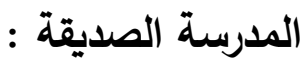

Friendship عرفت منظمة الأمم المتحدة للطفولة " اليونيسف " (• (†) المدرسة الصديقة بأنها مدارس تتوافر فيها مجموعة من المواصفات التي تضمن جعل تعلم التلاميذ فعالا

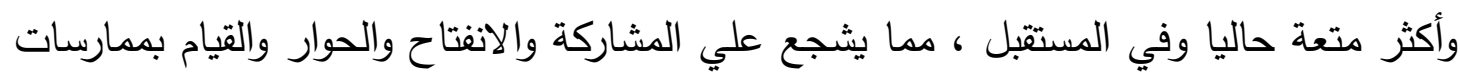
علمية وديموقراطية مرغوبة للتلاميذ وإعطاء المنظومة التعليمية الدعم الفاعل وشمولية التعليم.

أيضا تعرف وزارة التربية (1) ـ (1) المدرسة الصديقة بأنها مدارس ذات مواصفات خاصة ، تسعي للترحيب بالتلاميذ بأساليب مشوقة لجذبهم والتحاقهم بها ، والاحتفاظ بهر علي مقاعدها وتحترم

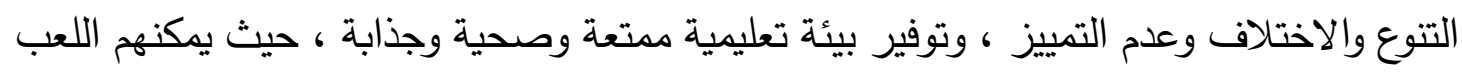

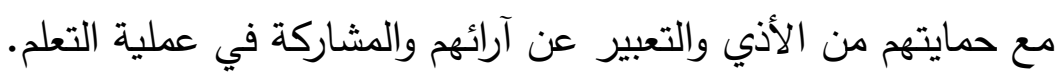

وتري ماجدة عبد الإله الخزرجي ( 19 • (1) أن مفهوم المدرسة الصديقة للطفل من المفاهيم المهمة

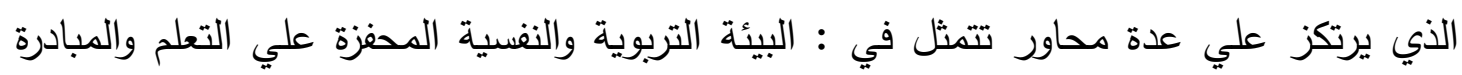

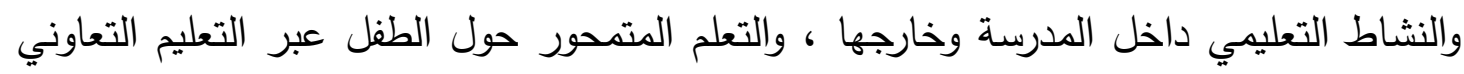

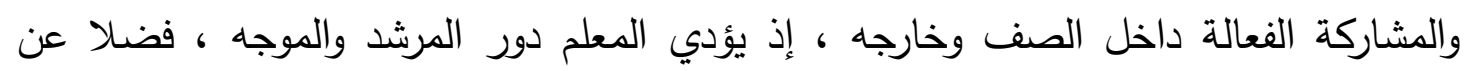

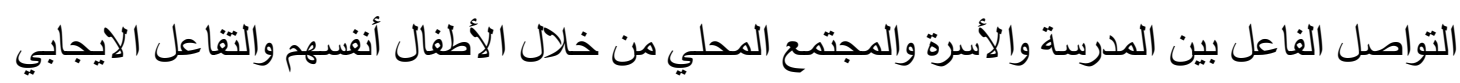
مع الفضاءات المحيطة به المتمثلة في البيئة المجتمعية والمحافظة علي مواردها واستدامتها. 
يقصد بالمدرسة الذكية Smart School بأنها المدرسة التي تستخدم تكنولوجيا المعلومات والوسائط

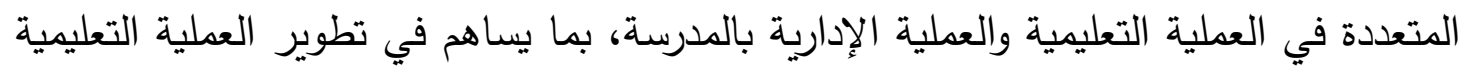
والإدارية بالمدرسة وتحسين مستواها. فعلي سبيل المثال المدرسة الذكية توفر معامل الحاسب الآلي وبرامج التدريب عليها لكل من

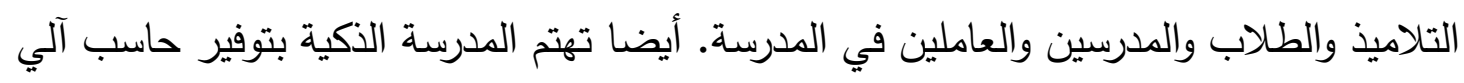

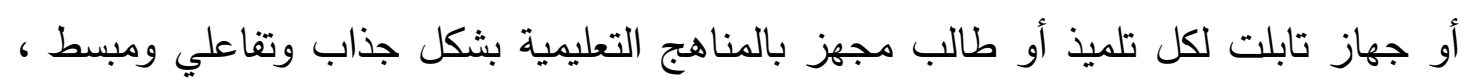
ومجهز بالامتحانات والاجابات عليها ل...

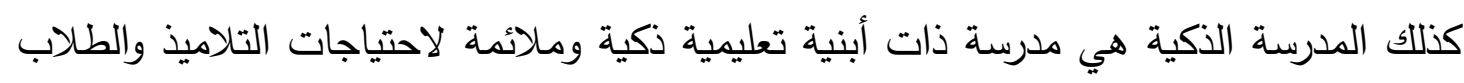

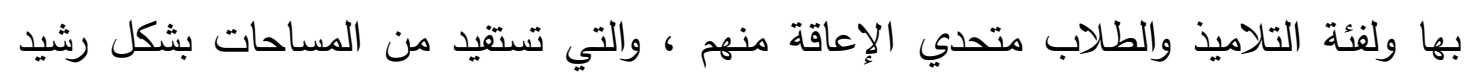
ومتتاسب وملائم للبيئة المحيطة والمناخ السائد فيها تتسم بالإبداع والابتكار وليست البهاب أبنية تقليدية

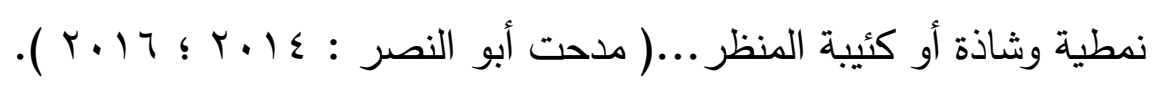

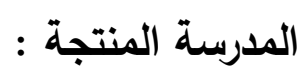
ظهر مفهوم المدرسة المنتجة Productive School أو المدرسة كوحدة إنتاجية من خلال سياسة

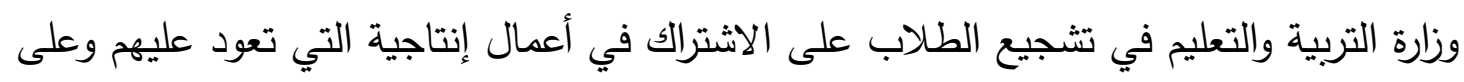

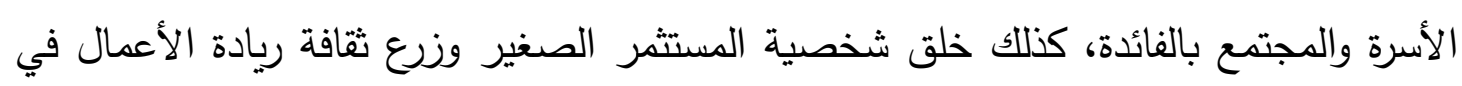

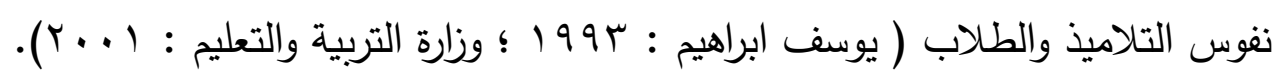

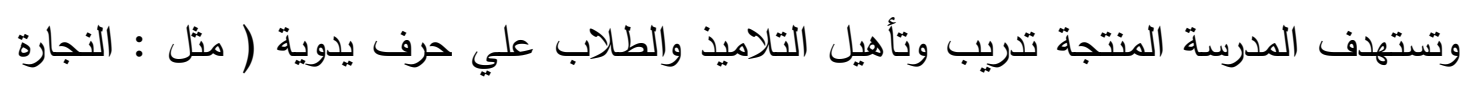

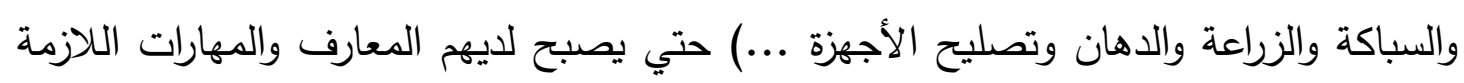

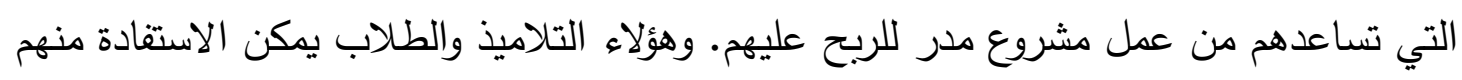

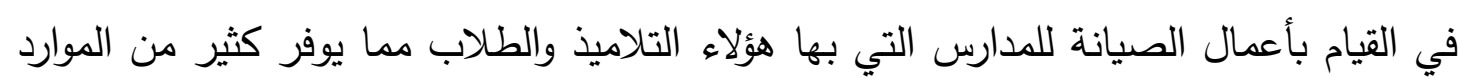
لهذه المدارس...أيضا في حالة عدم استكمال بعض التتلاميذ والطلاب للدراسة فإنه يستطيع بمزيد

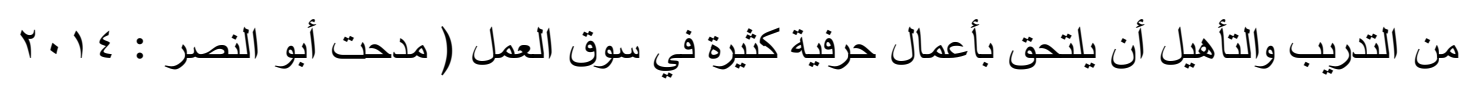
. ( r.

ولتدعيم فكرة المدرسة المنتجة قامت بعض وزارات التربية والتعليم في بعض الدول العربية ومنهم

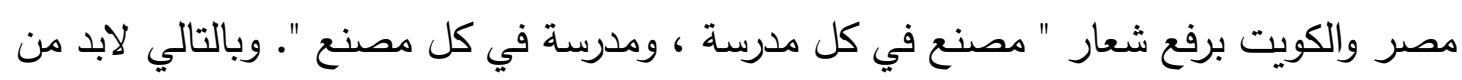

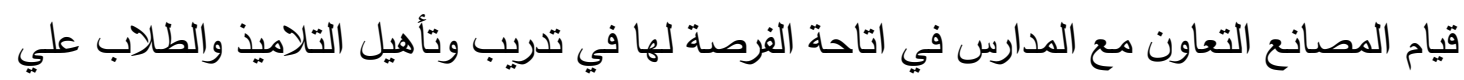

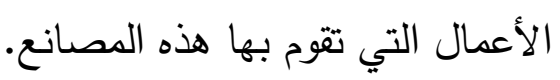


المدرسة الخضراء Green School أو الددرسة الصديقة للبيئة عليها أن تحافظ على البيئة

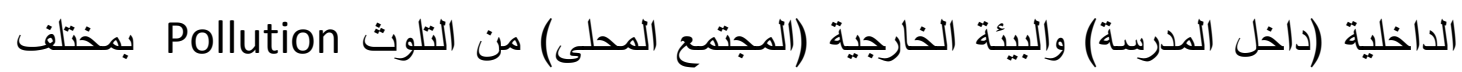

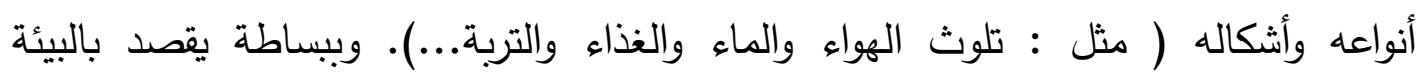
Environment

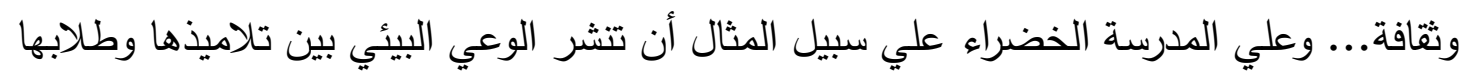
وبين سكان المجتمع المحلى المحيط، وذلك بواسطة قيامها بالعديد من الأنشطة والبرامج البيئية

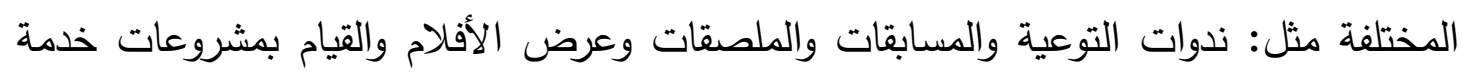
البيئة المدرسية وخدمة البيئة الخارجية.

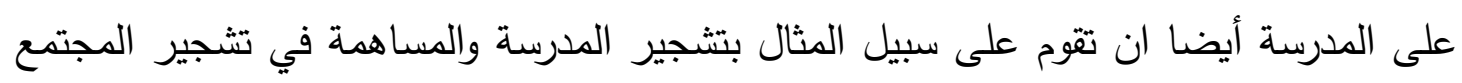

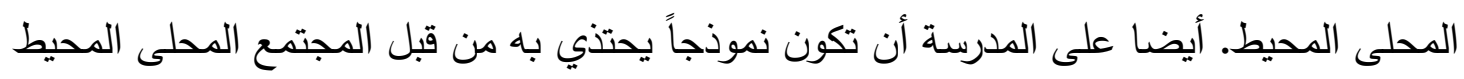

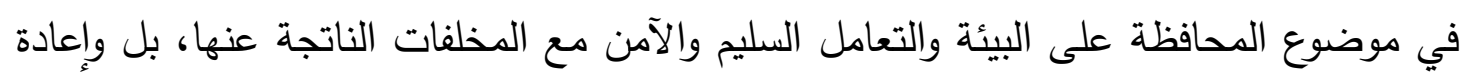

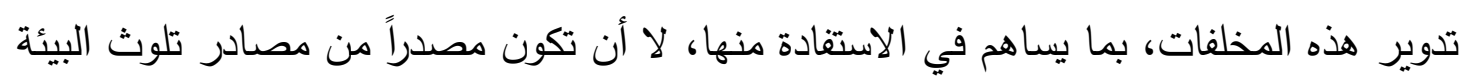

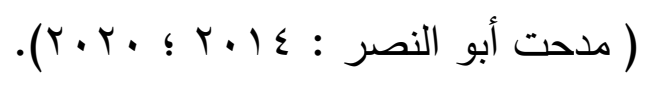

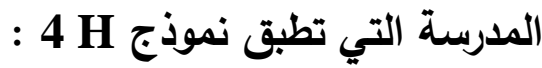

تهتم معظم دول الغرب المتقدمة بتطبيق شعار H4 في مؤسساتها التعليمية.

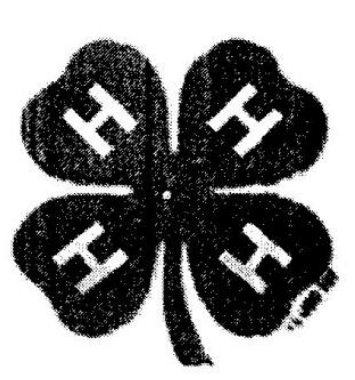

ويشير الشعار إلى : Head- Heart- Hand - Health أي أن المؤسسة التعليمية (مثل: رياض

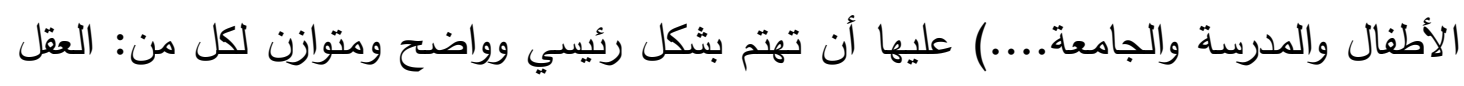

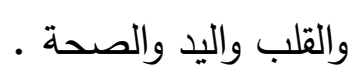
ويتم الاهتمام بالعقل من خلال إكساب التلميذ/ الطالب على سبيل المثال: بالمعرفة والمعلومات

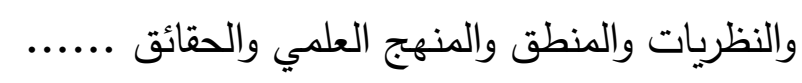
ويتم الاهتمام بالقلب من خلال حصص الدين والتربية القومية وجماعات النشاط الددرسي وبرامج رعاية الثباب (مثل: جماعات الشعر والرسم والنحت والقصة والإذاعة والمسرح ....). 
ويتم الاهتمام باليد من خلال تتمية المهارات اليدوية وتعليم وتدريب التلميذ/ الطالب على إحدى

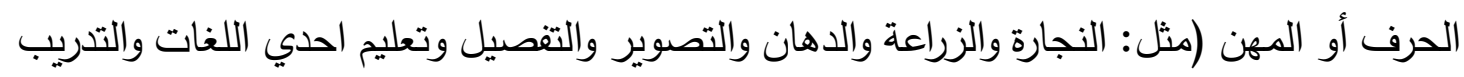

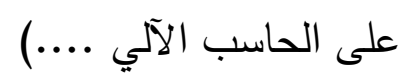

ويتم الاهتمام بصحة التلميذ والطالب من خلال على سبيل المثال: بالكثف الدوري والاكتشاف الافي

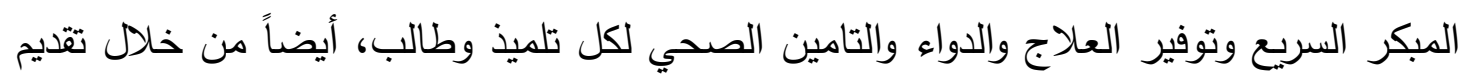
الوجبة الغذائية المناسبة والمتوازنة للتلاميذ وللطلاب مجاناً أو برسوم رمزية، والاهتمام بنظافة ولثئ

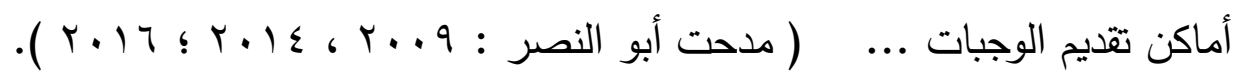
الأنثطة المدرسية :

يقصد بالأنشطة المدرسية School Activities أو الأنشطة غير التعليمية Non-Educational Activities

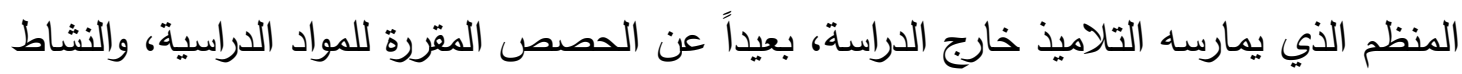

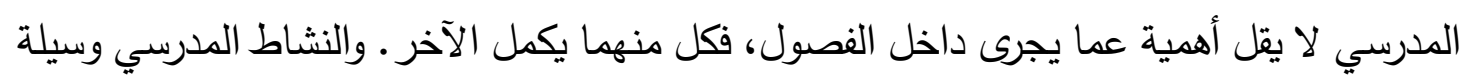

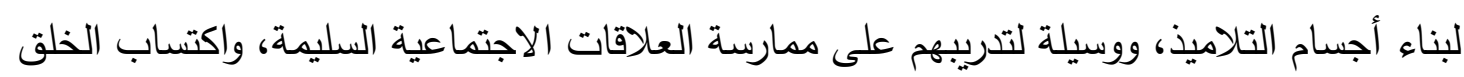

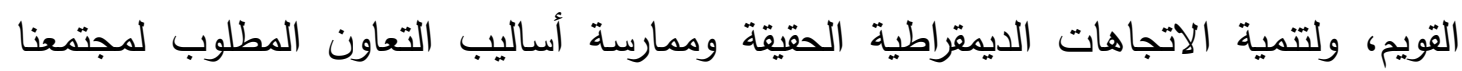

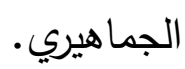
بمعني أن النشاط المدرسي جهد عقلي أو بدني أو اجتماعي يقوم به التلميذ أو الطالب باختياره

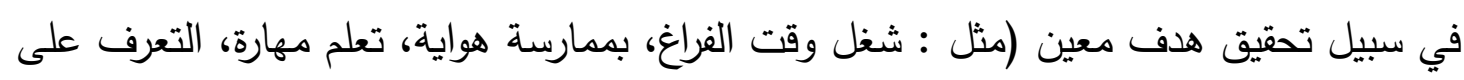

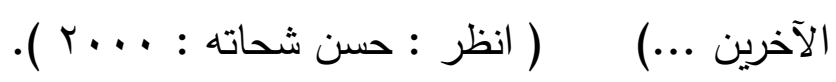

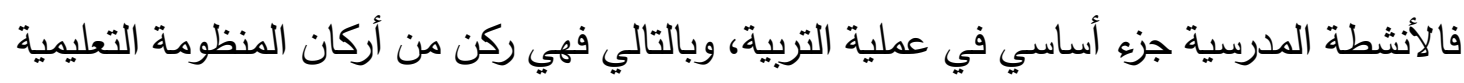

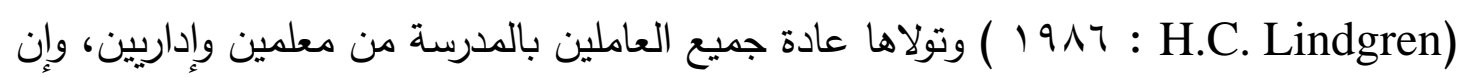

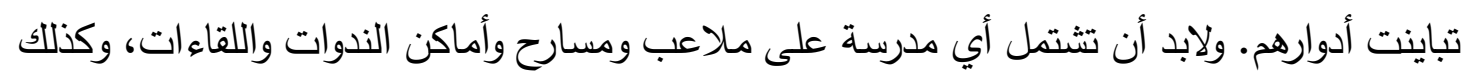

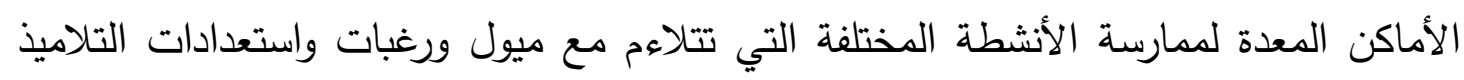
والطلاب، وتزيد من مهاراتهم وقدراتهم. إن ممارسة التلاميذ والطلاب للأنشطة المدرسية تمثل إحدى المحاور الرئيسية في تطوير المدارس.

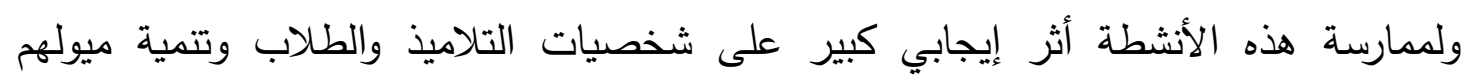

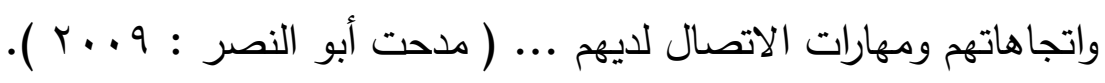

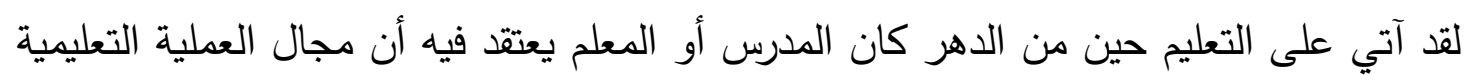

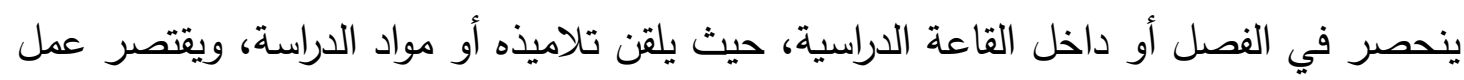

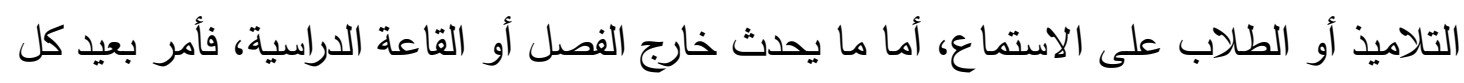




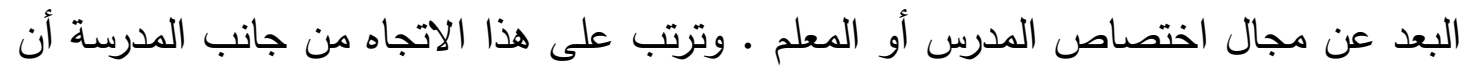

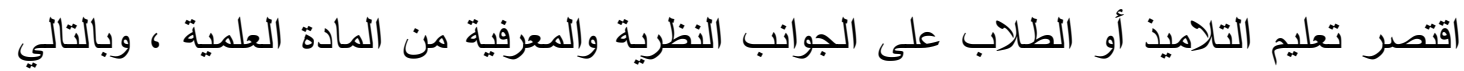

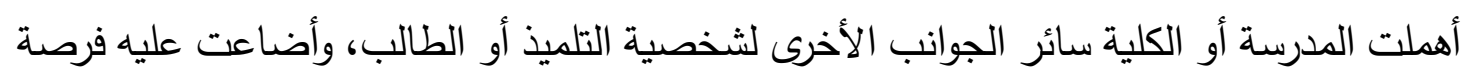
التعلم عن طريق العمل والحركة والنشاط ....

لقد كثفت كل البحوث في هذا الموضوع عن أهمية النشاط المدرسي في تدعيم العملية التعليمية

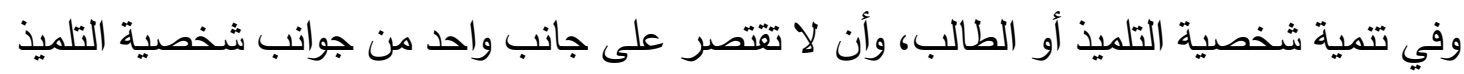

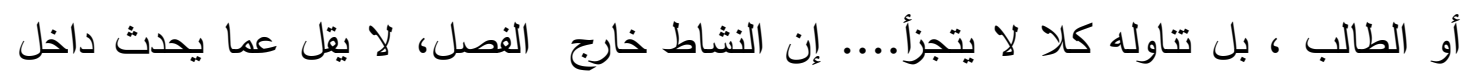

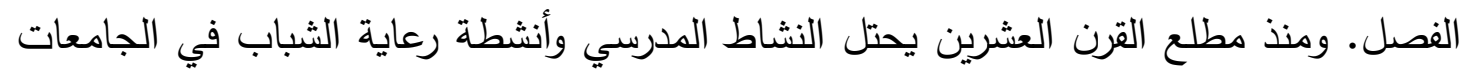

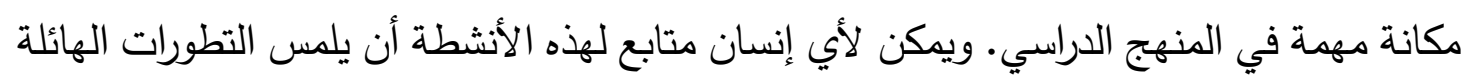
في هذا الحقل، الذي حدث به حراكا واسعاً شكلا ومضموناً . كما أنه بالتوجيه السليم يمكن ربط النشاط المدرسي بالتحصيل الدراسي، وبالتالي يكون النشاط التهاط الددرسي دافعاً إلى هذا التحصيل، ويؤدى إلى تكامل المواد الدراسية تكاملاً تاماً.

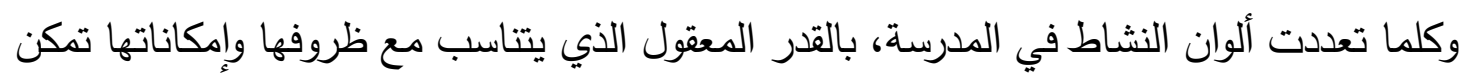
التلميذ من اختيار جماعة النشاط Activity Group التي تشبع برامجها ميوله، ويحقق نشاطها

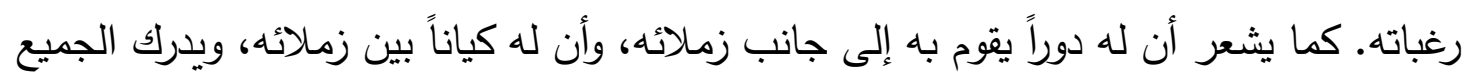

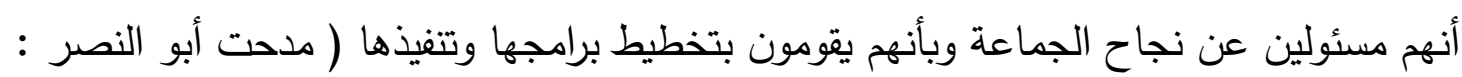
. ( r. $17 \leq r \cdot) \leq$

ومن المقترحات المطروحة لتوفير مزيد من الوقت لممارسة الأنشطة المدرسية في مؤسسات التعليم

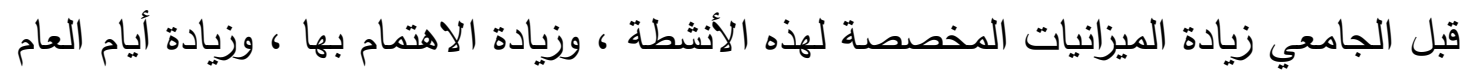

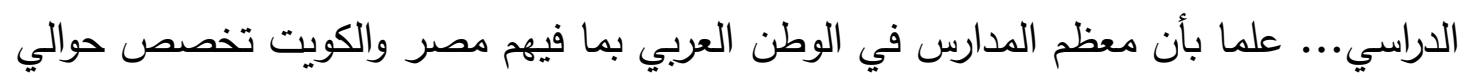

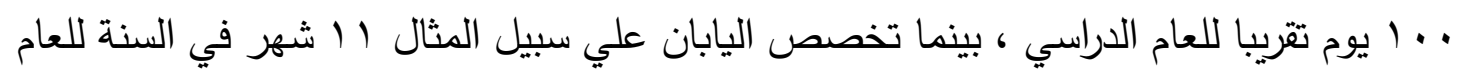
الدراسي.

\section{تنمية الابداع والابتكار والاختراع لاي التلاميذ والطلاب :}

Creation وأكد علي ضرورة اهتمام المؤسسات التعليمية بتتمية الابداع Innovation والابتكار والاختراع Invention لدي الأطفال والتلاميذ والطلاب. من منطلق أن الاهتمام بالإبداع والابتكار

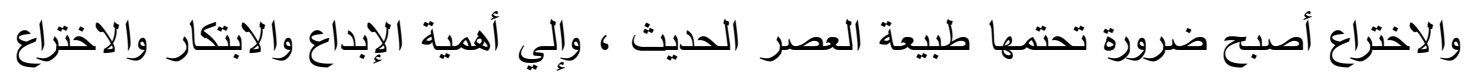

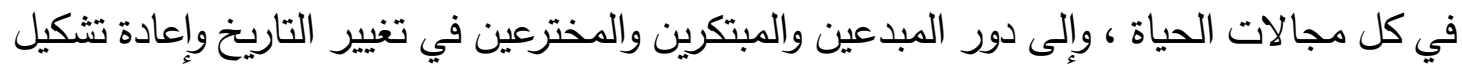

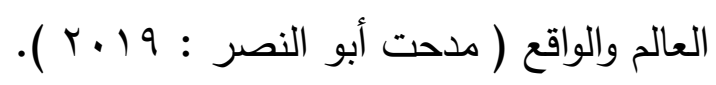


وتتنافس الدول المتقدمة فيما بينها في تشجيع الإبداع والابتكار والاختراع بهدف زيادة قوتها

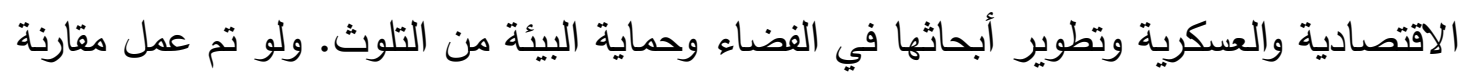

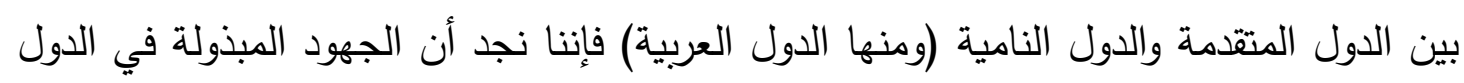

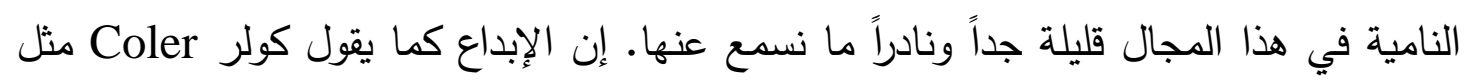

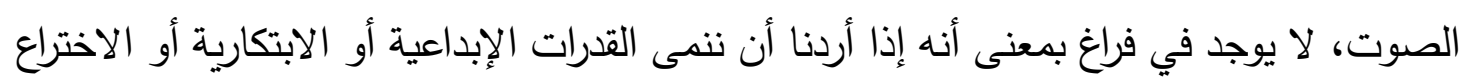

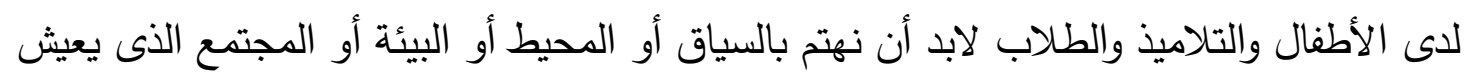
فيه هؤلاء. وتعتبر رياض الأطفال والمدارس جزء من هذا السياق أو المحيط أو البيئة.

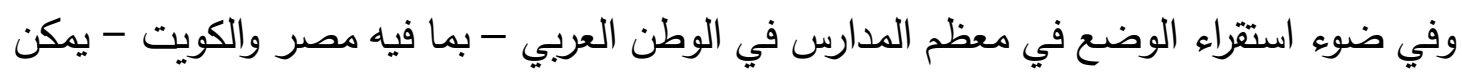

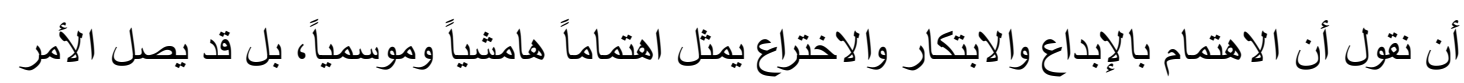

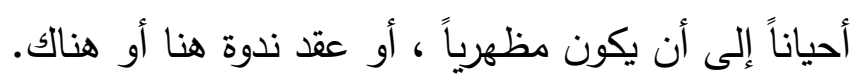

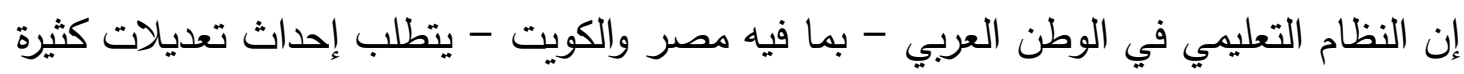
سواء أكانت في أسلوب المعاملة أو في طرق تدريس المادة الدراسية، أو في تحديد الأهداف

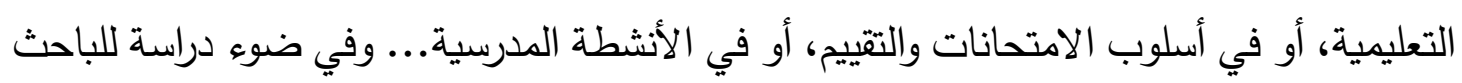

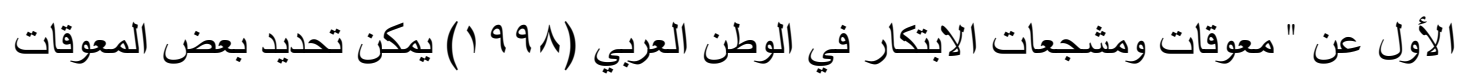

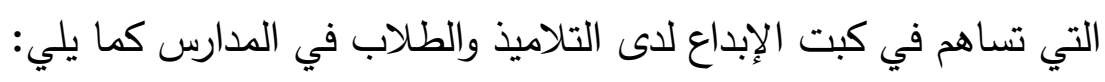
1- العدد الكبير في الفصل الواحد. r- ضعف الاهتمام بجماعات الهوايات والأنشطة.

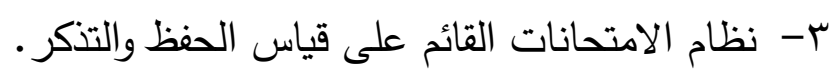
ع- ضعف الاهتمام بالمعامل التي يتوفر بها الأجهزة والمواد والأدوات.

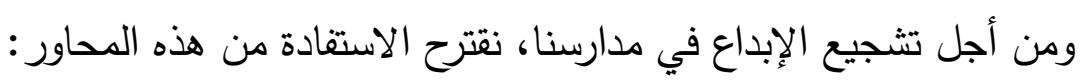

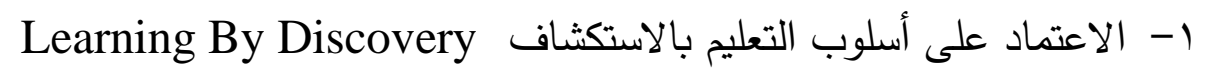
r- بالاهتمام بالتعليم الذاتي كelf Education r- عدم إجبار التلاميذ والطلاب على الالتزام بحرفية نموذج معين وكتاب معين. ع - احترام أسئلة وأفكار التلاميذ والطلاب. ه- حث وتثجيع التلاميذ والطلاب على إلقاء الأسئلة ومحاولة الوصول إلى الإجابة. צ- دمج التلاميذ والطلاب في جماعات الهوايات والأنشطة. - V - شجيع الطلاب والتلاميذ على الاستقلالية. 1- تشجيع القراءة الحرة. 9- تثجيع حب الاستطلاع والتجربة والملاحظة. 
• 1- وضع برامج للتفكير الإبداعي ضمن برامج الدراسة يتعلم منها التلاميذ والطلاب كيفية

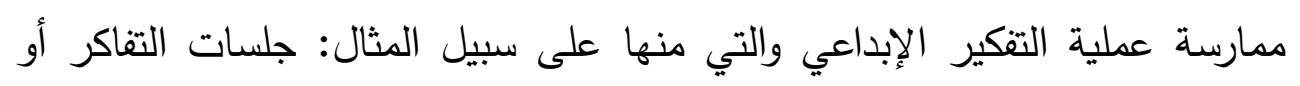

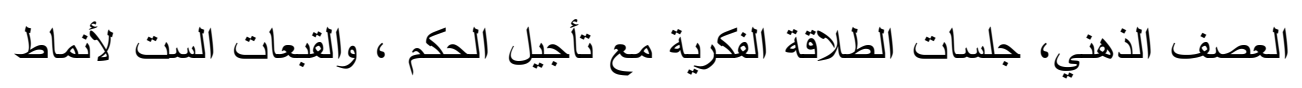

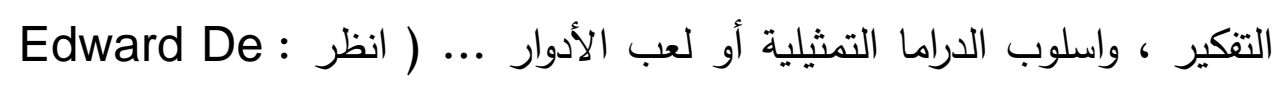

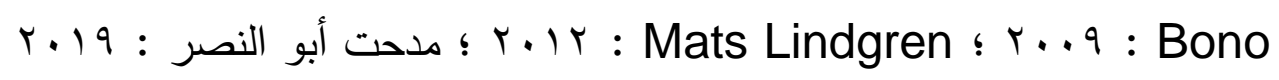

\section{مهنة الخدمة الاجتماعية في المجال المدرسي :}

ومن ملامح تطوير وتحسين التعليم قبل الجامعي ضرورة زيادة الاهتمام بمهنة الخدمة الاجتماعية

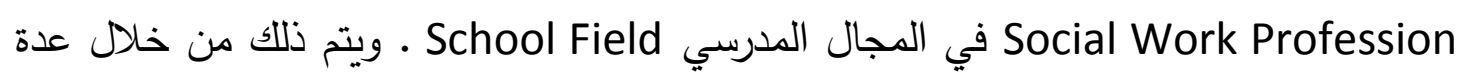

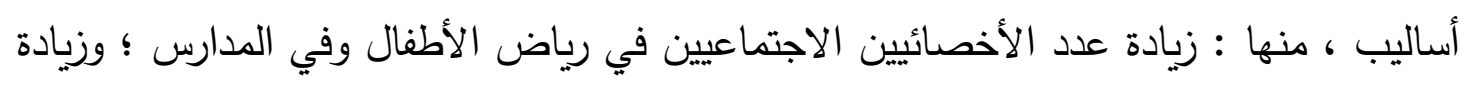

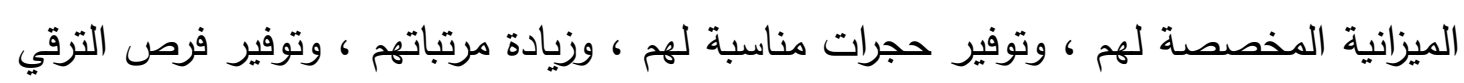

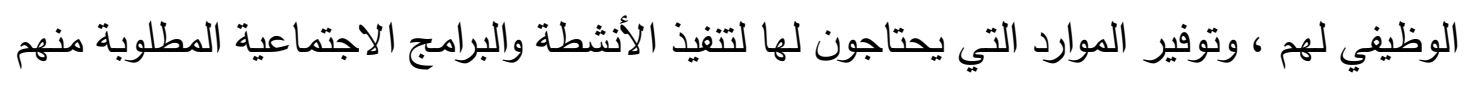

$$
\text { ومن تعريفات الخدمة الاجتماعية في المجال المدرسي : }
$$

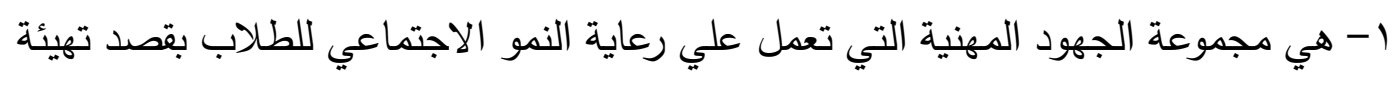

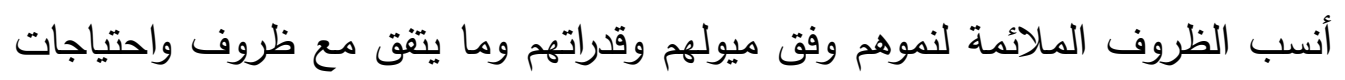

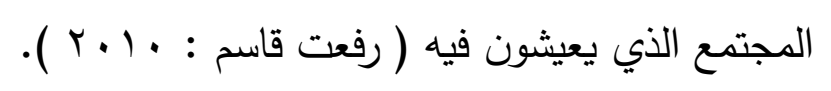

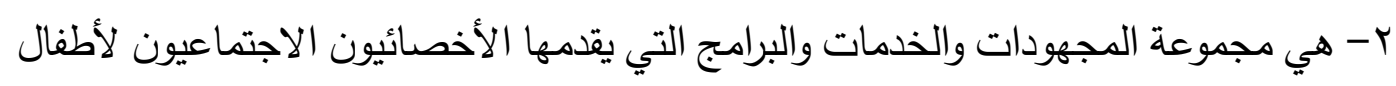

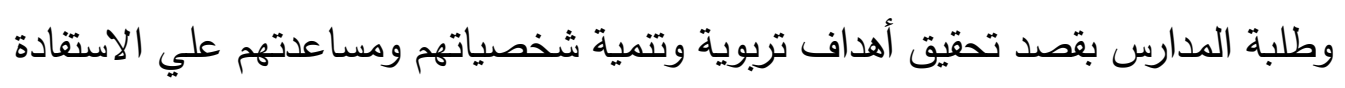

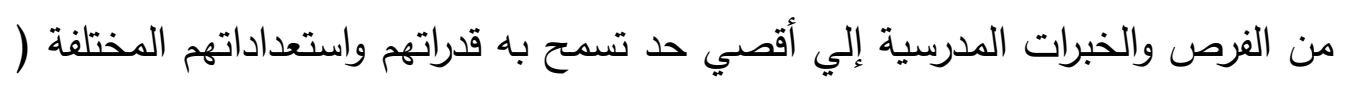

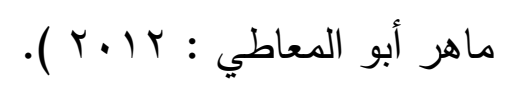

ويمكن تحديد الأهداف الرئيسية لمهنة الخدمة الاجتماعية في المجال الدرسي كالتالي :

$$
\begin{aligned}
& \text { 1-رعاية النمو الاجتماعي للأطفال وللتلاميذ وللطلبة في المدارس . }
\end{aligned}
$$

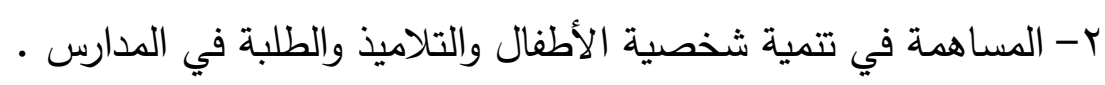

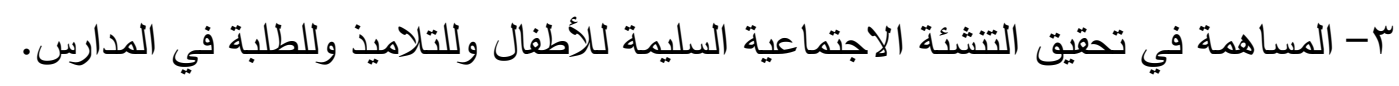
ع- مساعدة الأطفال والتلاميذ والطلبة في المدارس علي الاستفادة من الفرص والخبرات

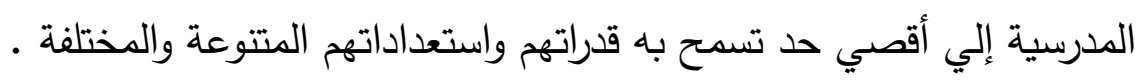

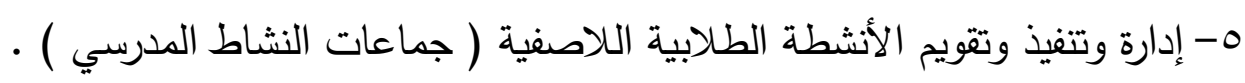

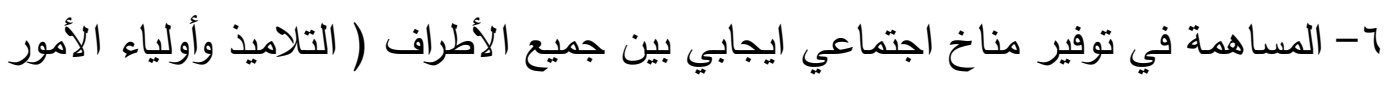

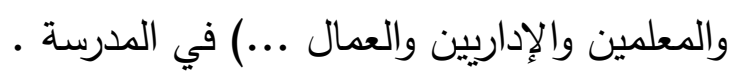


V- مساعدة المدرسة علي تحقيق أهدافها التعليمية والتربوية والاجتماعية والثقافية والتتويرية

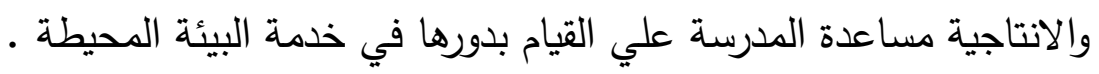

دور الأخصائي الاجتماعي Social Worker في المجال المدرسي :

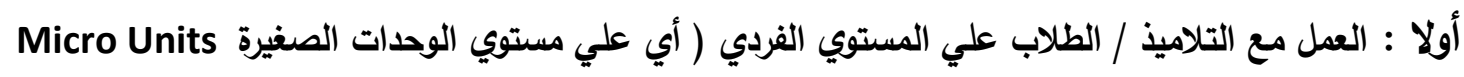

$$
\text { 1- بساعدة التلاميذ / الطلاب علي إشباع حاجاتهم }
$$

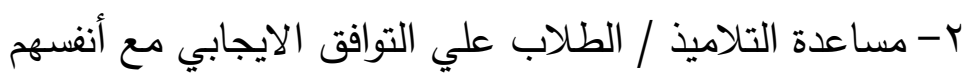

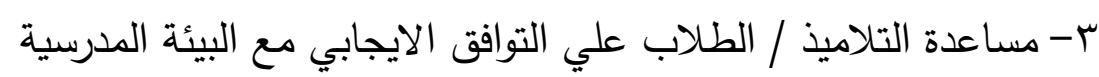

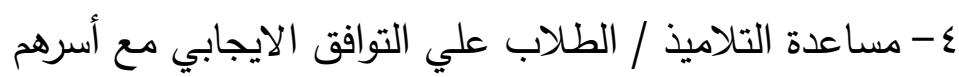

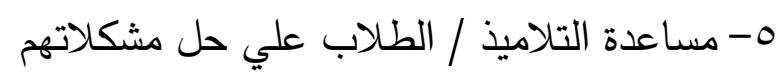

צ- إكساب التلاميذ / الطلاب بالاتجاهات والقيم والأخلاقيات الايجابية وتدعيمها. V- توعية التلاميذ / الطلاب بالاتجاهات والقيم والأخلاقيات السلبية وتوضيح مساؤها وتعديل

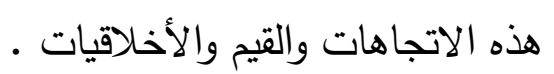

^- تدريب التلاميذ / الطلاب علي السلوكيات الايجابية وتدعيم هذه السلوكيات 9- توعية التلاميذ / الطلاب بالسلوكيات السلبية وتوضيح مساؤها وتعديل هذه السلوكيات.

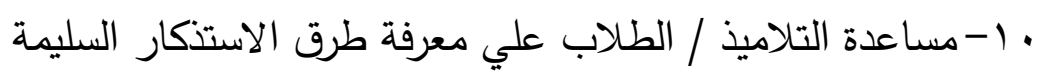
1)

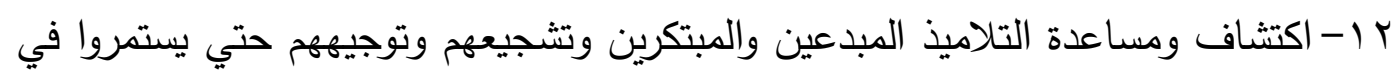

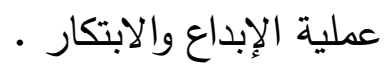
با - تحويل الحالات الصعبة ذات المشكلات المعقدة إلي مكاتب الخدمة الاجتماعية المدرسية

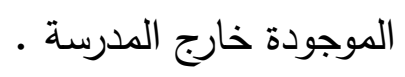

ثانيا : العمل مع التلاميذ / الطلاب علي المستوي الجماعي ( أي علي مستوي الوحدات

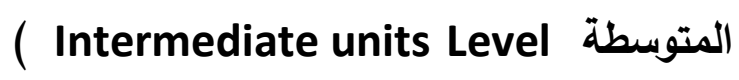
1- مساعدة التلاميذ / الطلاب علي شغل أوقات فراغهم بشكل مفيد ومناسب لكل من التلاميذ والعملية التعليمية والمدرسة والمجتمع ككل . 
r- تشجيع تكوين جماعات النشاط المدرسي المختلفة ( مثل : جماعة كرة القدم وجماعة كرة

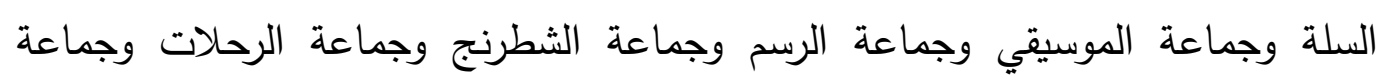

$$
\text { ك- الإثراف على هذه الجماعات . المعرات). }
$$

ع- مساعدة جماعات النشاط المدرسي على أتباع القيم والسلوكيات التربوية السليمة .

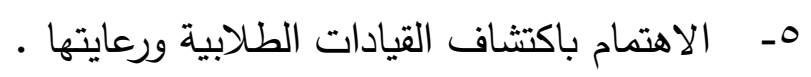

7- مساعدة جماعات النشاط المدرسي علي ممارسة الأنشطة المختلفة سواء داخل المدرسة أو

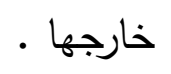

ثالثا : دور الأخصائي الاجتماعي مع المدرسة ككل والبيئة المحيطة بها ( أي علي مستوي

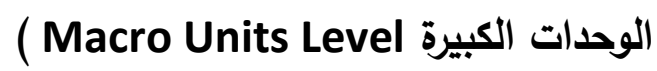

1-تدعيم وتتمية روح العمل الفريقي الفاعل داخل المدرسي ( بين الأخصائي الاجتماعي

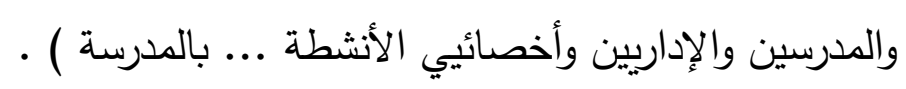

r- تدعيم وتتمية التعاون المثمر والمشترك في اتجاهين بين المدرسة وأسر التلاميذ / الطلاب.

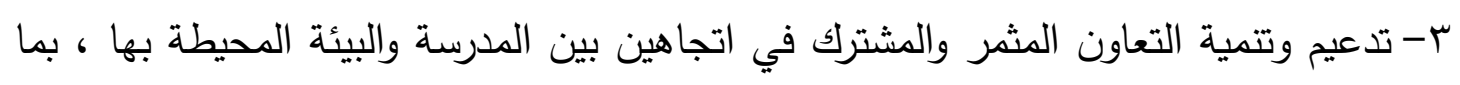

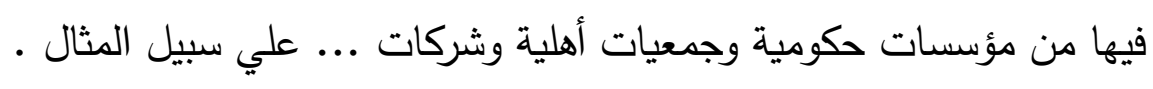

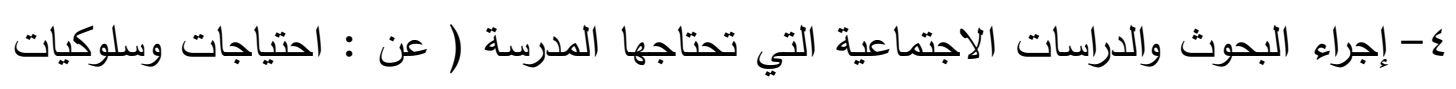

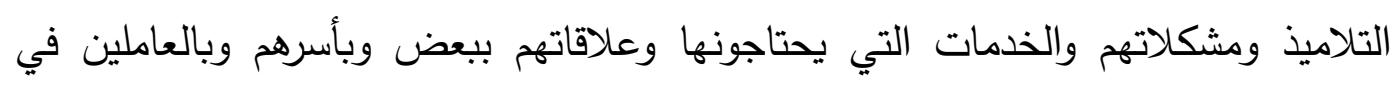

$$
\text { المدرسة وخاصة المدرسين علي سبيل المثال ). }
$$

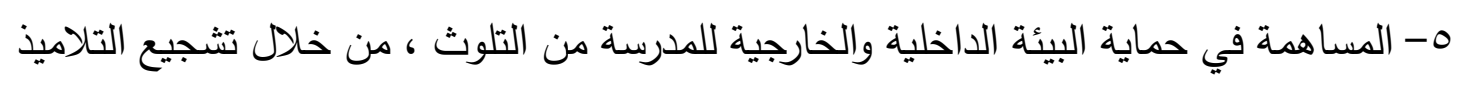

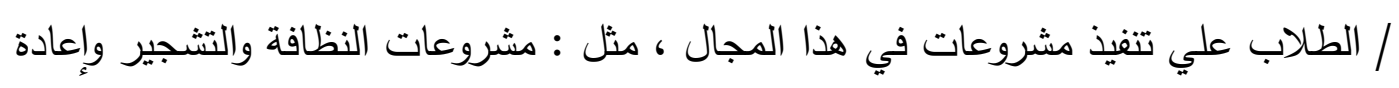

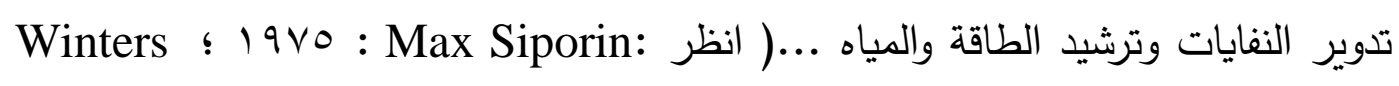
: David R. Dupper . . . : : Glasgow \& Freda Eston

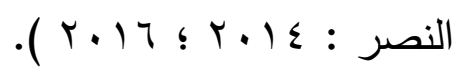

$$
\begin{aligned}
& \text { توصيات البحث : }
\end{aligned}
$$

ضرورة الاستفادة من المحاور والآليات السابقة وتطبيقها بالشكل السليم والمناسب من أجل تحسين

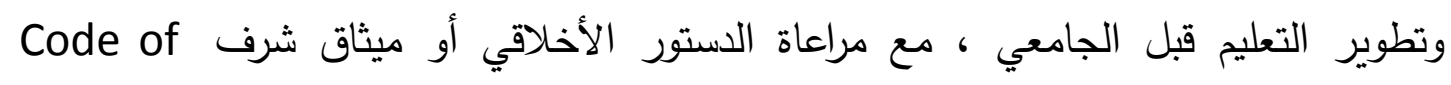
JEthics 
أيضا لابد من مراعاة معايير إدارة الجودة الثاملة Total Quality Management لما تتضمنها

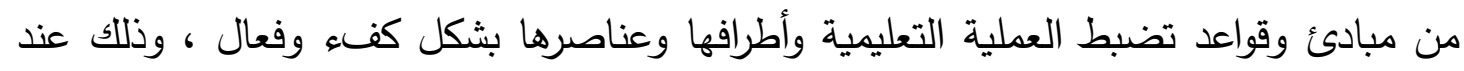
تطبيق هذه المحاور والآليات في مؤسسات التعليم قبل الجامعي.

أخيرا لابد من وضع مجموعة من المعايير Criteria أو المستويات Standards أو المؤشرات Indicators في مرحلة التعليم قبل الجامعي في عمليات التخطيط والتنفيذ والتقويم لكل الأنشطة والبرامج في التئي مؤسسات التعليم قبل الجامعي. فهذه المعايير علي سبيل المثال تمثل أطر مرجعية يتم في ضونئها

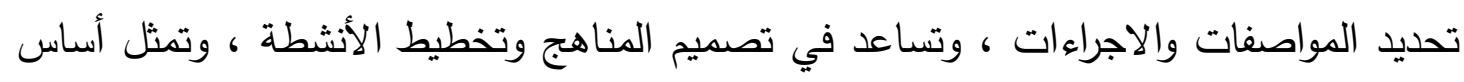
للتثييم ، وبداية صحيحة للتقويم ل... مراجع البحث:

\section{أولا : المراجع العربية}

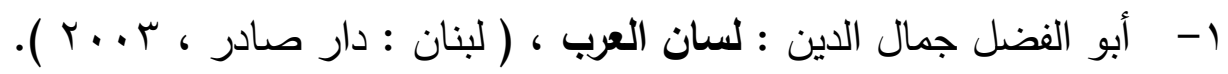

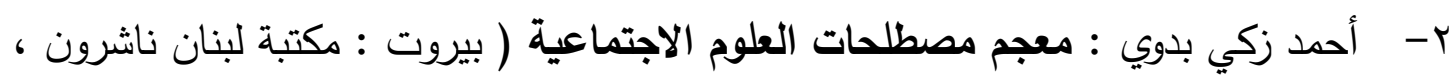
. (1994

r- أحمد فتحى سرور: تطوير التعليم في مصر (القاهرة: قطاع التعليم, وزارة التربية والتعليم, . (1) 919

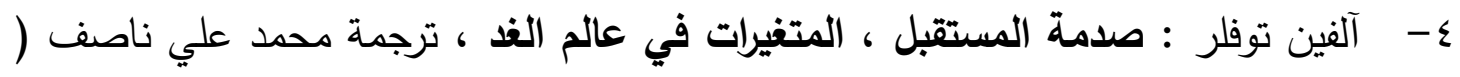

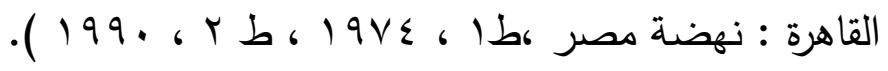

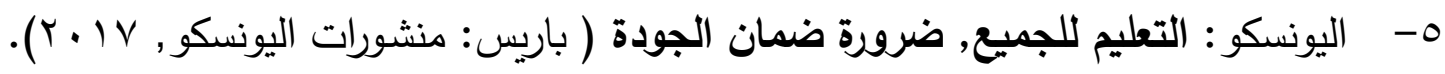

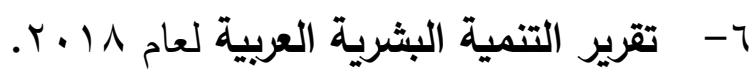

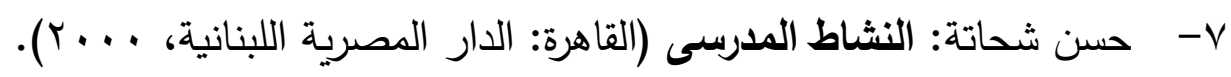

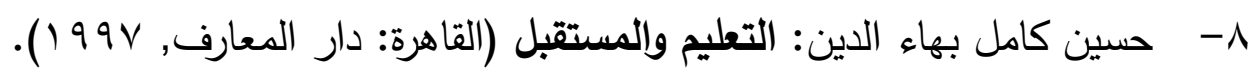

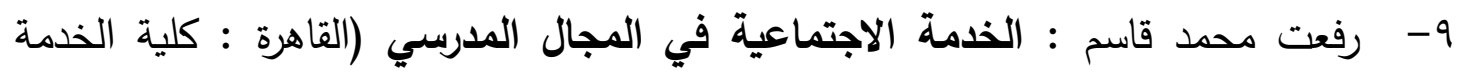

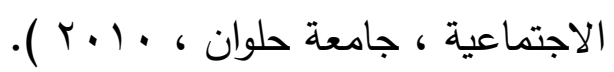

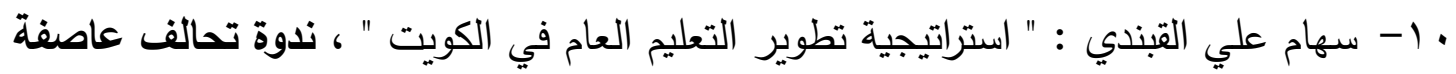

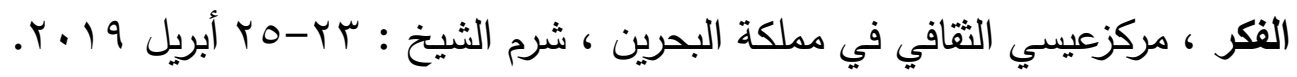


11- ماجدة عبد الأله الخزرجي : " المدارس الصديقة للطفل ودرجة توظيفها لمهارات التعليم

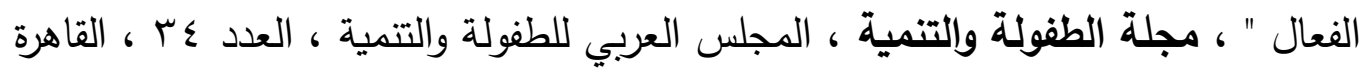
.r.19:

Y ا - ماهر أبو المعاطي علي : الخدمة الاجتماعية في المجال التعليمي ( القاهرة : كلية الخدمة

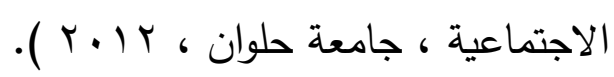

با - مجمع اللغة العربية : المعجم الوجيز ( القاهرة : طبعة وزارة التربية والتعليم ، 1999 التحان ).

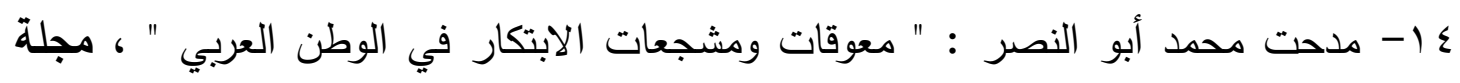

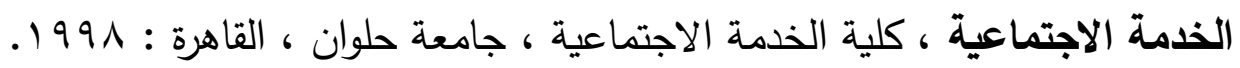

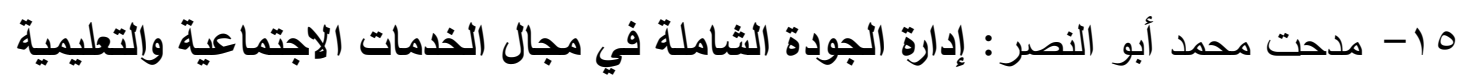

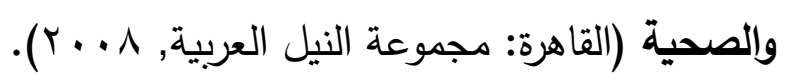
14 - مدحت محمد أبو النصر: أساسيات إدارة الجودة الثاملة (القاهرة: دار الفجر للنشر

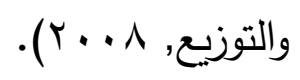
V IV مدحت محمد أبو النصر: تطوير المدارس (القاهرة: الروابط العالمية للنشر والتوزيع, $\cdot(r \cdot 9$

11 - مدحت محمد أبو النصر : إدارة الأنثطة والخدمات الطلابية في المؤسسات التعليمية

$$
\text { (القاهرة: دار الفجر للنشر والتوزيع, 9 . . ب). }
$$

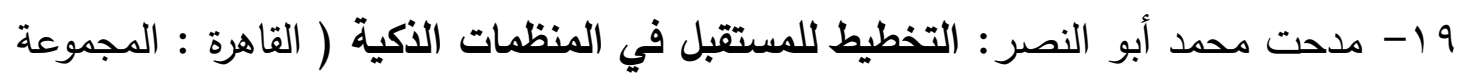

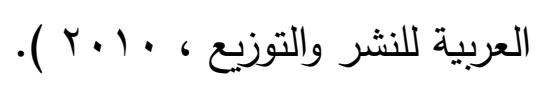

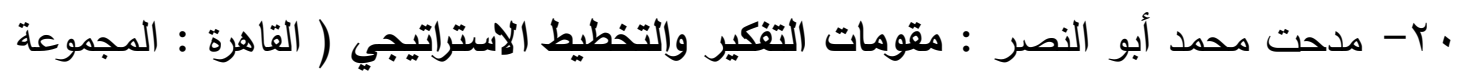

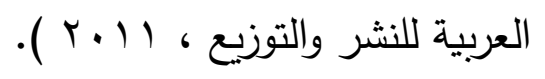

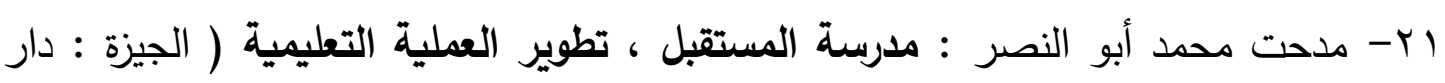

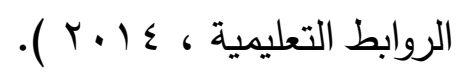

Y ب- مدحت محمد أبو النصر : الخدمة الاجتماعية في المجال المدرسي (القاهرة: المجموعة

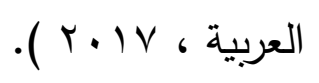

بr- مدحت محمد أبو النصر : تنمية التفكير الابداعي والابتكاري ( القاهرة : المجموعة العربية

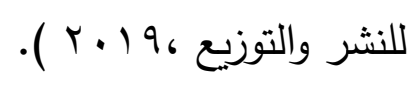

ع ץ- ممدوح محمد عبد الحميد : الثقافة العلمية ومعايير تضمينها في المناهج الاراسية ( القاهرة

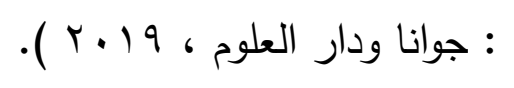


هץ- منظمة الأمم المتحدة للطفولة : دليل المدارس الصديقة للطفل ( القاهرة وتونس : مكتب

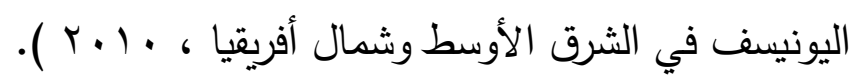

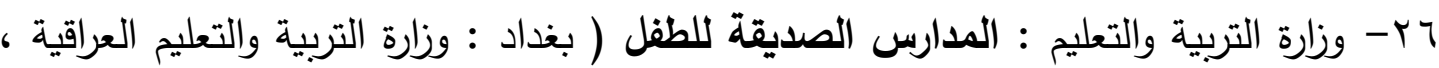

$$
\cdot(r+1)
$$

VY

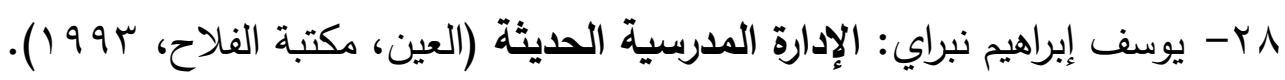
ثانيا : المراجع الأجنبية

1- Alvin Toffler,: Future Shock ( London : Bantam Books , 1970 ) .

2- David R. Dupper: School Social Work (N. Y. : John Wiley \& Sons, INC.,2006 ).

3- Edward De Bono : Think Before its too late (London : Vermilion : 2009).

4- H.C. Lindgren: Non-Educational Activities in Schools (N. Y.: John Wiley \& Sons, 1986).

5- John Welly: The New Schools (N. Y.: Free Press, 2008).

6- Karen K. Ashman: Introduction to Social Work (Australia: Thomson, $2^{\text {nd }}$. Ed., 2007).

7- Lane Jennings : “ The Futures Research Directory śs and Periodicals ", World Future Society Journal , No. 94 , 1993.

8- Mats Lindgren : Make Your Success Now Creativity in the 21st Century ( UK : Macmillan, 2012 ).

9- Max Siporin: Introduction to Social Work (N. Y.: Macmillan Publication Co., Inc,1975).

10- Oxford: English Arabic Readers Dictionary (Oxford: Oxford Press, 2019).

11- P . Dalin: How Schools Improve? ( London / N. Y.: Cassell, 1994 ).

12- R. Barth: Improving Schools from Within (San Francisco: Jossey Bass, 1990). 
13- Robert L. Barker: The Social Work Dictionary (Washington, DC.: N.A.S.W., $5^{\text {th }}$ Ed., 2003) .

14- S. C. Purkey \& M.S. Smith: Effective Schools : a Review (N. Y. :Free Press, 2007).

15- Sarah H. Peeper \& et. al.: Good Schools for Young Children (N. Y. : Macmillan Co., 1994 ).

16- Winters W. Glasgow \& Freda Eston: The Practice of Social Work in Schools (N.Y.: Free Press, $2^{\text {nd }}$. Ed., 2000). 